\title{
False allegations of abuse and Munchausen syndrome by proxy
}

\author{
Roy Meadow
}

\begin{abstract}
Fourteen children from seven families are reported for whom false allegations of abuse were made by the mother. Twelve children were alleged to have incurred sexual abuse, one both sexual and physical abuse, and one physical abuse alone. Thirteen of the children had incurred, or were currently victims of, factitious illness abuse invented by the mother. The one child with no history of factitious illness abuse had a sibling who had incurred definite factitious illness abuse.

The false allegations of abuse did not occur in the context of parental separation, divorce, or custody disputes concerning the children. They occurred in the context of Munchausen syndrome by proxy abuse. The age of the children, 3 to 9 years, was older than the usual age for Munchausen syndrome by proxy abuse. The mother was the source of the false allegations and was the person who encouraged or taught six of the children to substantiate allegations of sexual abuse.

(Arch Dis Child 1993; 68: 444-447)
\end{abstract}

A large proportion of allegations of abuse, particularly sexual abuse, which are investigated thoroughly do not lead to further proceedings; they prove to be unsubstantiated. (In the USA $45 \%$ of allegations of sexual abuse are unsubstantiated. ${ }^{1}$ ) However, even when allegations are proved to be completely false, that does not mean that the allegations have been mischievous or deliberately false, rather that events, and a child's behaviour or statements, have been misinterpreted. For a proportion of unsubstantiated cases there remains the possibility that abuse may have occurred, but there is insufficient evidence to pursue the matter further.

It is acknowledged that false allegations of abuse are more common at the time of divorce and disputes about custody of children. ${ }^{1-4}$ In the bitterness and sadness of parental separation, false allegations occur. Outside that context, false allegations are thought to be rare.

Here seven families are described in which false allegations of abuse occurred in the wider context of Munchausen syndrome by proxy abuse of the children. The factitious abuse was one of several factitious problems invented by the mother for her child, though in each case the false allegations of abuse probably caused more
Table 1 Number of children in each family, their sex, and the number incurring false allegations of abuse and/or of illness

\begin{tabular}{|c|c|c|c|c|c|}
\hline \multirow{2}{*}{\multicolumn{2}{|c|}{$\begin{array}{l}\text { Children in } \\
\text { family }\end{array}$}} & \multicolumn{2}{|c|}{ Sex } & \multirow{2}{*}{$\begin{array}{l}\text { False } \\
\text { abuse }\end{array}$} & \multirow{2}{*}{$\begin{array}{l}\text { Factitious } \\
\text { illness }\end{array}$} \\
\hline & & $F$ & $M$ & & \\
\hline & $\begin{array}{l}3 \\
3 \\
2 \\
2 \\
2 \\
2^{\star} \\
1\end{array}$ & $\begin{array}{l}1 \\
2 \\
1 \\
1 \\
1 \\
1 \\
1\end{array}$ & $\begin{array}{l}2 \\
1 \\
1 \\
1 \\
1 \\
1\end{array}$ & $\begin{array}{l}3 \\
3 \\
2 \\
2 \\
2 \\
1 \\
1\end{array}$ & $\begin{array}{l}3 \\
2 \\
2 \\
2 \\
2 \\
1 \\
1\end{array}$ \\
\hline Total & 15 & 8 & 7 & 14 & 13 \\
\hline
\end{tabular}

^One child incurred false abuse only, the other false illness only.

stress and abuse of the child than the associated factitious illnesses.

The seven families were encountered during a 14 year period in which the author was involved with about 300 children who had incurred factitious illness abuse. A smaller number of children, about whom allegations of sexual abuse were made by their mothers, are not included in this paper because, although the allegations could not be substantiated, there was uncertainty among the professionals involved about whether the children might have incurred sexual abuse. The cases reported are ones in which the allegations of abuse were proved to be false or considered, with a very high degree of probability, to be false after full assessment and investigation.

\section{Factitious abuse}

The seven families contained eight girls and seven boys, all of whom had suffered either factitious illness or false allegations of abuse. Table 1 shows that, in five families, all 10 children suffered both factitious illness and false allegations of (sexual) abuse. In one family one child suffered only from factitious illness and the sibling incurred only false abuse. Of the 14

Table 2 The main fabricated illnesses in 14 children

Apnoea/seizures, $n=4$ (including one maternal admission of suffocation)

Haematuria, $n=3$

Severe allergy, $n=3$

Hyperactivity, $n=2$

Diarrhoea/faecal incontinence, $n=2$

Drug overdose, $n=2$

Dermatitis artefacta, $n=2$

Other (dyslexia, haemoptysis, fever, and visual problems), $n=t$ 
children who suffered from false allegations all except one had suffered, or were incurring, fabricated illness. The main fabricated illnesses are listed in table 2 . All the children were healthy and free from symptoms when away from their mother.

At the time when it was realised that the allegations of abuse were false, there had not been previous realisation that 11 of the children had incurred, or were suffering, factitious illness. However for three children the doctors involved were aware of the possibility of factitious illness before the false abuse came to light. For one child the investigation of factitious illness led to realisation that false allegations were also being made about sexual abuse.

The age of the child at the discovery of false abuse ranged from 3-9.2 years (mean $5 \cdot 2$ years). For eight children the allegations of abuse had been repeated for less than six months. For four children the allegations of abuse had been made repeatedly over a period of one and a half to four years. The allegations were made by the child's natural mother with whom the child was living. The nature of the allegations made were as follows: sexual abuse alone $(n=12)$, sexual abuse plus physical abuse $(n=1)$, and physical abuse alone $(n=1)$.

For seven of the children the mother alleged that the child had been abused by more than one person. The alleged perpetrators of the abuse were: unrelated men not living in home $(n=13$, usually specific men were named, including three older children in the neighbourhood of the home), former partner/husband $(n=4)$, and current husband living at home $(n=1)$.

The allegations were made by the child's mother to one or more of the following: social services, National Society for Prevention of Cruelty to Children, police, doctors, school teachers.

Usually the allegations were made in person by the mother. For one child the allegation was made by anonymous letters that were later traced to the mother. In another case numerous anonymous telephone calls were made to different agencies; the calls were traced to the mother. There is circumstantial evidence that six children had been trained by their mothers to disclose realistic stories of sexual abuse. In two cases tape recordings were found that indicated that the children, with the help of a tape recording machine, had either been rehearsed to practise the disclosure or been taught to provide the disclosure story. Two children had minor injuries to their perineum, not characteristic of sexual abuse, and it was believed that the injuries had been caused by the mother.

\section{The mothers}

From information obtained from other family members, relatives and from medical records, it emerged that two of the mothers were compulsive liars about most aspects of their past and present life. Three other mothers were regard $-d$ as being prone to exaggeration and moderate deceit. Two mothers had gross somatising disorder including previous false paralysis and severe pseudoepilepsy. ('Somatising disorder' is being used here to describe either a somatoform disorder, as defined by the Diagnostic and Statistical Manual of Mental Disorders Third Edition, Revised, or a factitious disorder.) Three had moderate somatising disorder and a long history of personal illnesses that had neither yielded the usual positive findings on examination nor been ameliorated by standard therapies. One mother, who had neither a history of deceit nor somatising disorder, had a history of self harm and substance abuse. Thus six of the seven mothers had either some degree of somatising disorder themselves or were known by their relatives to tell lies frequently.

At the time of the initial false allegations, four of the mothers were living in the family home without a partner, two were living with the children and their father, and one was living with the children and a new partner.

\section{Consequences}

At the time of the initial allegations, usually of sexual abuse, the notified agency or professional did not know about the previous fabrication within the family nor the details of the mother's history. Thus the children were subject to the investigations, physical examinations, and disclosure interviews that are necessary to identify sexual abuse. Because of the repetitive nature of the allegations, and at the mother's insistence, many of the children underwent massive repetitive investigation. The details of the fabrications emerged slowly and from different sources over a period of two months to two years. During this time the usual procedures in relation to child abuse had occurred including wardship for the children of two families, care orders, and legally enforced supervision. In addition alleged perpetrators were subjected to police interrogation.

At a later stage when the probability of false allegations was being investigated, three mothers admitted inventing the stories. of abuse. Two mothers are not known to have made an admission but, after confrontation and social work intervention, they were allowed to continue with custody of their children; both the allegations of abuse and the factitious illnesses have ceased. The other two mothers, who made the allegations anonymously, were traced by identifying their letters and telephone calls. After confrontation one stopped both factitious illness and allegations of abuse for a period of nine months before resuming again. The other stopped and is not thought to have resumed during the next two years.

\section{Discussion}

That false allegations of sexual abuse may occur at the time of contested divorce and disputes concerning custody of the children is well known. In North America it is reported that such allegations occur in rather more than $2 \%$ of custody disputes and that at least one third of the allegations are considered to be false.' An additional large proportion are unsubstantiated. There are several possible explanations.

At the time of parental separation, there tends to be mistrust and misunderstanding between 
the partners that may lead to false allegations which are not deliberate. At the same time there is reason to expect an increase of true allegations as sexual abuse will sometimes be the reason for separation, or separation will provide the physical circumstances in which the child may suffer abuse. Moreover children who did not disclose abuse before divorce may feel able to do so when living away from the perpetrating parent. Nevertheless the number of false allegations at the time of divorce is a cause for concern and has generated considerable study and some helpful literature. ${ }^{5-7}$

Some of those analysing false allegations at the time of custody disputes have drawn a parallel to Munchausen by proxy factitious illness abuse. ${ }^{8-10}$ Rand, who has summarised this work clearly, describes false allegations occurring at the time of custody disputes as 'contemporary' Munchausen syndrome by proxy, comparing it with 'classic' Munchausen syndrome by proxy in which the child is alleged to suffer illness. " She draws a parallel between the well established warning signs of factitious illness abuse and the warning signs that may be observed in false allegations of sex abuse. ${ }^{12}$ There are many reports of the distress that children incur from repeated investigations and assessments after false allegations of sex abuse. Further unhappiness follows when fathers, and occasionally mothers, are separated from their children by the courts because of false allegations of abuse (a tragic and typical case is described in the book Bad Moon Rising ${ }^{13}$ ).

Those with personal or professional experience of parental separation and divorce are unlikely to be surprised that, within the unhappiness, bitterness and selfishness of such disputes, false allegations are made and that the true needs of children are sometimes forgotten by one or other partner, and the children suffer. Nevertheless it is worth remembering that, in most custody disputes, allegations of abuse are not made and that it is an abnormal minority of parents that makes false allegations.

Allegations of sexual abuse in the context of occult rituals and allegations of ritual sex abuse are.often false (after reading the collection of articles in volume 15 of Child Abuse and Neglect 1991, pages 163-196, many will conclude that most are false). But false allegations of 'ordinary' sexual abuse, outside the context of marriage breakdown and child custody disputes, have been considered rare. This paper reports 14 children who suffered as a result of false allegations. For seven of the children there is certainty that the allegations were false in that the mother admitted the falsification and the circumstances and details of the abuse were proved to be impossible. For the other children extensive and (unhappily) repeated examination and investigation, by professionals with particular experience and skill in the diagnosis of sexual abuse, made it virtually certain that the allegations were false.

These cases all occurred in families in which the children had suffered definite factitious illness abuse. In each case it was the mother who had invented or caused the false illness. Two of the children were alleged to have incurred physical abuse, but 13 were alleged to have incurred sexual abuse. There were strong reasons for believing that two of the girls had been injured by the mother to mimic sexual abuse. (There have been previous reports of mothers using a tampon or fingers to enlarge the vaginal orifice to impress the medical assessor. ${ }^{12}{ }^{14}$ ) None doubt that children can be taught to recite stories and adopt inappropriate roles. There are many instances of children having been 'brain-washed' by their mothers to be allergic to a wide variety of substances, to consider themselves to be unable to walk, or to adopt specific illnesses or disabilities. ${ }^{1516}$ Similarly mothers may teach their child a story of sex abuse that can then be disclosed to the assessor. In two homes tapes were found recorded on which the child was being helped (or taught) by the mother to relate disclosure of sex abuse and being praised when that was done well.

Wakefield and Underwager have described the harmful effects of non-abused young children being taught to produce false disclosure information. ${ }^{14}$ With repeated telling, the story becomes even more embellished and the child genuinely believes it. In the course of subsequent assessments the repeated telling and questioning causes the child difficulty in distinguishing reality from unreality and the process may lead to a child becoming psychotic. Both the mother and the assessors are driving the child deeper into a fantasy world.

Munchausen syndrome by proxy abuse usually involves young children and commonly starts in the first year of life. ${ }^{15}$ It is noteworthy that the allegations of false abuse involved older children and therefore an integral part of the abuse, in all but one family, was the indoctrination of the child with a story that abuse had occurred. It was only in the course of prolonged investigations that it became apparent that these stories lacked authenticity and detail, and contained inappropriate language; and that the children did not express, or indeed have, the associated feelings which would have accompanied the alleged abuse. The mothers themselves were most active in repeating the story of abuse and insisting on further assessment. They did not show the empathy and concern that parents usually feel when their child has been abused. Three of the mothers were insistent on more assessment by different doctors, social workers, and psychologists despite several previous competent assessments. They were prepared to demand ever more assessment and examination of their children however unpleasant that might be.

The mother who made a massive number of anonymous telephone calls alleging abuse resembles those described by Rogers who were considered to be suffering from delusional disorders. ${ }^{17}$ However the other mothers were dissimilar and more typical of some mothers who perpetrate conventional Munchausen syndrome by proxy abuse. They tended to be deceitful about many aspects of their personal and past life and to thrive on being the centre of attention or in the midst of crises. Wakefield and Underwager have studied the personality and characteristics of parents who make false accusations of 
sexual abuse in custody disputes. ${ }^{18}$ As with perpetrators of Munchausen syndrome by proxy abuse the parents rarely have mental illness, but are much more likely to have a personality disorder such as histrionic, borderline, passive aggressive, or paranoid. The first two personality types were among the commonest that we identified in a series of 46 mothers who perpetrated Munchausen syndrome by proxy abuse. ${ }^{19}$

For eight of these 14 children the false accusations of abuse caused more investigation and distress than the previous or concurrent false allegations of physical illness. For the other six the allegations of abuse were an extra hardship on top of the suffering they incurred as a result of false illness. We need to find ways of preventing such suffering and to detect false abuse speedily.

The current awareness and media attention given to child sexual abuse has led to a plethora of allegations and those involved in assessing them are well aware of the difficulties. The literature validating allegations is well reviewed in a recent article by Heiman; that work should reduce the chance of mistakes. ${ }^{20}$ Nevertheless those involved with families need to be aware that, just as a small proportion of mothers invent or cause illness in their child, so there will be some who invent abuse. And, just as there are a minority of mothers who indulge in doctor shopping, leading their child to a succession of specialists or alternative sources of medical care, and always ready to subject their child to yet more investigations and treatments, so there are a minority of mothers who do the same with social workers, psychologists, and doctors in relation to sexual abuse.

It is reasonable to suggest that genuine sexual abuse will sometimes occur in children who have incurred, or are incurring, Munchausen syndrome by proxy abuse. To date this has not been recorded, which suggests that it is extremely uncommon. Although there is significant comorbidity, in terms of neglect and physical abuse in children who have suffered factitious illness abuse, sexual abuse has not featured. ${ }^{21}$ Part of the reason for this may be that the perpetrator of factitious illness abuse is nearly always the mother, whereas most sexual abuse is by men. Nevertheless it can be expected that, very occasionally, sexual abuse will occur together with factitious illness abuse.

The false allegations described in this paper were easier to detect because the mothers also invented false illness stories about their children. However, just as a mother may provide a false story of one illness event such as haematuria, diarrhoea or seizure, it is likely that there will be some mothers who will merely invent false abuse; that will make detection more difficult. The best way of identifying these cases early will be a combination of the standard methods for validating accusations of abuse combined with the standard methods for investigating suspected Munchausen syndrome by proxy abuse. ${ }^{22} 23$ If those had occurred early for the children reported in this paper, they would have suffered much less. If other family members, particularly the father, the mother's mother and the mother's sister had been interviewed earlier, the assessors would have been aware that two of the mothers had long standing histories of being gross deceivers, and three of producing unreliable stories. A check of the health records of the other children in the family (and in Britain the general practitioner records are the key document providing a guide to all the medical and hospital encounters the child has had) would have revealed the likelihood of factitious illness for the children. Discussion with the general practitioner would have yielded important medical information (in relation to unproved strange illness) for four of the mothers. Therefore providing that there is an awareness that false allegations occasionally occur, and a comprehensive assessment occurs, the deception should be uncovered before the children have suffered unduly.

I am grateful to the colleagues who involved me with these families and to Mandy Jones for her help.

1 Myers JEB. Allegations of child sexual abuse in custody and visitation litigation: recommendations for improved fact finding and child protection. Foumal of Family Law 198990; 28: $1-41$.

2 Kaplan SL, Kaplan SJ. The child's accusation of sexual abuse during a divorce and custody struggle. Hillside $\mathcal{f}$ Clin during a divorce and custo.

3 Thoennes N, Pearson J. A difficult dilemma: responding to sexual abuse allegations in custody and visitation disputes In: Besharov DJ, ed. Protecting children from abuse and neglect. Springfield: CC Thomas, 1988: 91-112.

4 Thoennes N, Pearson J. Summary of findings from the sexual abuse allegations project. In: Nicholson EB, ed. Sexual abuse allegations in custody and visitation cases. Washington, DC: American Bar Association, 1988: 1-36.

5 Thoennes N, Tjaden PG. The extent, nature, and validity of sexual abuse allegations in custody/visitation disputes. Child Abuse Negl 1990; 14: 151-63.

6 Jones D, McGraw JM. Reliable and fictitious accounts of sexual abuse of children. Foumal of Interpersonal Violence 1987; $2: 27-45$.

7 Schuman DC. Psychodynamics of exaggerated accusations: positive feedback in family systems. Psychiatric Annals 1987 17: 242-7.

8 Goodwin J. Sexual abuse: incest victims and their families. Boston: John Wright - PSG Inc, 1982.

9 Libow J, Schreier $H$. Three forms of factitious illness in children: when is it Munchausen syndrome by proxy? Am $\mathfrak{F}$ Orthopsychiatry 1986; 56: 602-10.

10 Herman-Giddens $M$, Berson N. Harmful genital care practices in children. A type of child abuse. FAMA 1989; 261: 577-9.

11 Rand DC. Munchausen syndrome by proxy: integration of classic and contemporary types. Issues in Child Abuse Accusations 1990; 2: 83-9.

12 Rand DC. Munchausen syndrome by proxy - a complex type of emotional abuse responsible for some false allegations of child abuse. In: Wakefield H, Underwager R, eds. Solomon's dilemma, false allegations in divorce and custody. Springfield: CC Thomas, 1993 (in press).

13 Ferguson D. Bad Moon Rising. Nashville: Winston-Derek Publishers, 1988.

14 Wakefield H, Underwager R. Accusations of child sexual abuse. Springfield: CC Thomas, 1988.

15 Meadow R. Munchausen syndrome by proxy. Arch Dis Child 1982; 57: 92-8.

16 Rosenberg DA. Web of deceit: a literature review of Munchausen syndrome by proxy. Child Abuse Negl 1987; 11: $547-63$.

17 Rogers ML. Delusional disorder and the evolution of mistaken sexual allegations in child custody cases. American foumal of Forensic Psychology 1992; 10: 47-69.

18 Wakefield H, Underwager R. Personality characteristics of parents making false accusations of sexual abuse in custody disputes. Issues in Child Abuse Accusations 1990; 2: 121-36.

19 Bools CN, Neale BA, Meadow SR. Munchausen syndrome by proxy: a study of individual psychopathology. Child Abuse Negl (in press).

20 Heiman ML. Annotation: putting the puzzle together: validating allegations of child sexual abuse. $\mathcal{f}$ Child Psychol Psychiatry 1992; 33: 311-29.

21 Bools C, Neale B, Meadow R. Co-morbidity associated with fabricated illness (Munchausen syndrome by proxy). Arch Dis Child 1992; 67: 77-9.

22 Meadow R. Management of Munchausen syndrome by proxy. Arch Dis Child 1985; 60: 385-93.

23 Neale B, Bools C, Meadow R. Problems in the assessment and management of Munchausen syndrome by proxy. Children and Society 1991; 5: 324-33. 